\title{
Flumazenil, a benzodiazepine receptor antagonist, in the reversal of conscious sedation following gastroscopy. A placebo controlled, dose finding study
}

\author{
Lloyd Sutherl.AND, MD, NOEl HershField, MD, EldDON SHAFFer, MD, \\ Lorne Price, MD, Deanne Dean, PhD, Margaret Light, PhD
}

L Sutherland, N HershField, E ShafFer, L PRice, D DEAN, M Light. Flumazenil, a benzodiazepine receptor antagonist, in the reversal of conscious sedation following gastroscopy. A placebo controlled, dose finding study. Can J Gastroenterol 1991;5(6):209-213. This double-blind, placebo controlled, study assessed the efficacy and safety of flumazenil, a benzodiazepine antagonist, in reversing diazepam-induced sedation in 60 patients undergoing endoscopy. Patients were randomly assigned to one of six treatment groups (placebo, 5,10 , 15,20 or $25 \mu \mathrm{g} / \mathrm{kg}$ flumazenil). Patient psychomotor function was determined using four standard assessments - Trieger, digit substitution, track tracing and cancellation tests. Flumazenil was well tolerated by all patients. All doses of flumazenil were superior to placebo in reversing sedation. No significant differences were detected between the various treatment groups. Forty-five minutes after the flumazenil infusion, there were no differences between flumazenil- and placebo-treated patients in psychomotor function. Flumazenil is a safe, effective medication which reverses diazepam-induced conscious sedation. For most patients $0.5 \mathrm{mg}$ given intravenously will reverse sedation. (Pour résumé voir page 210)

Key Words: Clinical trial, Diazepam, Flumazenil, Placebo controlled, Randomized study

Division of Gastroenterology, Foothills Hospital, University of Calgary, Calgary, Alberta; and Hoffmann-La Roche Limited, Mississauga. Ontario

Correspondence and reprints: Dr LR Sutherland, Room 1751, 3330 Hospital Drive NW, Calgary, Alberta T2N 4NI. Telephone (403) 220-4500, Fax (403) 283-4740

This paper was presented in part at the International Symposium on Flumazenil in Geneva, Switzerland

Received for publication June 13, 1991. Accepted November 21, 1991

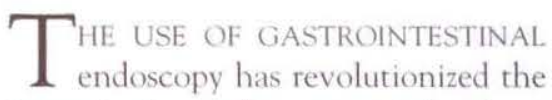
investigation and treatment of patients with gastrointestinal disease. Significant improvements in the design and flexibility of the instruments have improved patient acceptance; however, most patients, when offered the opportunity, choose conscious sedation when undergoing endoscopic procedures $(1,2)$.

Diazepam has long been considered to be the drug of choice for patients undergoing endoscopy (3). It has a proven record of safety and efficacy but its use is complicated by thrombophlebitis (4). Recently, a water soluble benzodiazepine, midazolam, was introduced (5-7). Because of its water solubility, midazolam has been associated with less thrombophlebitis. Its amnesic potential appears to be better than diazepam $(8,9)$. Another alternative is Diazemuls (Pharmacia) which contains diazepam in a lipid solution.

Although both drugs are safe, to date there has been no readily available 
Le flumazénil, antagoniste des récepteurs des benzodiazépines, dans l'interruption d'une sédation consciente après gastroscopie. Étude contrôlée contre placebo visant à déterminer la posologie

RESUME: La présente étude à double insu contrôlée contre placebo visait à déterminer l'efficacité et l'innocuité du flumazénil, antagoniste des benzodiazépines, utilisé pour interrompre la sédation induite par le diazépam chez 60 patients subissant une endoscopie. Les patients ont été répartis au hasard parmi six groupes de traitement $(5,10,15,20,25 \mu \mathrm{g} / \mathrm{kg}$ de flumazénil ou placebo). La fonction psychomotrice a été évaluée à l'aide de quatre examens standard (épreuve de Trieger, tests de substitution de chiffres, de tracé et de barrage). Le médicament a été bien toléré par tous les patients. Toutes les doses de flumazénil ont donné des résultats supérieurs au placebo. Aucune différence significative n'a été décelée parmi les divers groupes traités. Quarante-cinq minutes après la perfusion de flumazénil, on n'a noté aucune différence dans la fonction psychomotrice entre les groupes de patients ayant reçu du flumazénil et les sujets témoins. Le flumazénil est un médicament sûr et efficace, qui annule la sédation consciente induite par le diazépam. Dans la plupart des cas, il suffit d'administrer $0,5 \mathrm{mg}$ par voie intraveineuse pour obtenir ce résultat.

reversal agent for benzodiazepines. Such a medication would have a variety of uses: it could be used to reverse sedation in patients who have received an excessive amount of benzodiazepine during a procedure; it could be given to patients who do not wish to remain in the recovery room until the sedation gradually wears off; and it could be used in the treatment of intentional benzodiazepine overdose.

Diazepam and midazolam, as with the other benzodiazepines, act through enhancement of transmission at the GABAinergic synapses in the central nervous system. This interaction at the GABA receptor affects the chloride channel resulting in sedation and amnesia (10). Flumazenil is a water soluble imidazobenzodiazepine which can antagonize the sedative effects of benzodiazepines through competitive binding to the benzodiazepine receptor $(11,12)$. It has a serum mean half-life of 54 mins. Recent reports have suggested that it is effective in reversing sedation induced for minor surgical procedures $(13-16)$ and in the treatment of acute overdoses (17). Early studies suggested that a broad range of doses up to $10 \mathrm{mg}$ were required to effectively compete with the benzodiazepine receptor.

The present study assessed the effectiveness of flumazenil via a doubleblind, placebo controlled, dose finding study in patients undergoing routine upper intestinal endoscopy.

\section{PATIENTS AND METHODS}

Sixty patients who were scheduled to undergo gastroscopy for investigation of various gastrointestinal symptoms were randomly assigned to one of six groups (placebo, $5,10,15,20$ or 25 $\mu \mathrm{g} / \mathrm{kg}$ flumazenil). A log was not kept of patients who refused to participate in the study. To ensure uniformity, all patients were between 18 and 60 years old, within $15 \%$ of ideal body weight (1983 Metropolitan Tables of Height and Weight), and were not ingesting any chronic medication (particularly $\mathrm{H}_{2}$ antagonists or benzodiazepines). Women of childbearing potential had to be using an effective means of contraception (oral contraceptives or an intrauterine device). All patients were in American Society of Anesthesiologists class I or II [18]. Patients with a history of chronic illness or chemical dependency were excluded. The protocol was reviewed by the Conjoint Ethics Committee of the University of Calgary, Alberta.

Prior to endoscopy and as part of the routine pharmacological safety evaluation, patients underwent routine laboratory assessment as well as ECG and chest $\mathrm{x}$-ray. Immediately before endoscopy the patients performed four stand- ard psychomotor function tests (Trieger [19], digit symbol substitution [20], track tracing $[21]$ and cancellation tests [21]) to assess their ability to perform simple tasks with pencil and paper under the supervision of the study nurse. No premedicants were given. Patients were taken to the endoscopy suite where the throat was anesthetized with xylocaine $1 \%$ spray. Diazepam $(0.15 \mathrm{mg} / \mathrm{kg})$ was given intravenously to produce the desired sedative effect (relaxed, responsive to commands, somewhat somnolent with nystagmus). If required, additional diazepam (up to $0.15 \mathrm{mg} / \mathrm{kg}$ ) was given.

At the conclusion of the endoscopy and 15 mins after diazepam, the test medication (flumazenil or placebo) was infused over 2 mins. Five minutes after the test medication was given, the psychomotor evaluations were repeated, and were continued every 10 mins until 90 mins after the injection.

Prior to discharge patients completed a brief questionnaire regarding their recall and assessment of the endo. scopy. Two to three days after the procedure the patients returned for repeat laboratory assessment including ECG. Adverse events were recorded by the study nurse at the time of endoscopy and at the patient interview during the repeat visit.

Statistical methods: Descriptive variables were analyzed using comparison of means and standard deviation. Psychometric measures recorded during the trial were analyzed using repeated measures analysis of variance and analysis of covariance with treatment group as the cofactors. Categorical outcome measures were analyzed using Pearson $\chi^{2}$ tests to determine differences between the treatment groups, as well as McNemar's $\chi^{2}$ to determine differences between treatment visits.

\section{RESULTS}

Sixty patients (31 males and 29 females) participated in the study with 10 patients randomly assigned to each treatment group. Patients were enrolled over a 15 month period from December 1986 to March 1988 (Table 1). There were no significant differences between treatment groups in terms of age, sex. 
weight or total dose of diazepam required (Table 1).

The results of the Trieger and track tracer tests are shown in Figure 1. For the sake of simplicity only one dose of flumazenil $(15 \mu \mathrm{g} / \mathrm{kg})$ and placebo are presented. Essentially all doses of flumazenil were found to be superior to placebo. Trieger testing could not demonstrate significant differences among the flumazenil groups, but all flumazenil-treated patients recorded significantly fewer dots missed compared to placebo treated patients (Figure 1). Patients who received vehicle only demonstrated significant impairment with the track tracer test compared with patients receiving flumazenil (Figure 1). This improvement was no longer evident 45 mins after the procedure. Analysis of patient performance measured by digit substitution and cancellation tests confirmed the effectiveness of all doses of flumazenil against placebo for the initial $45 \mathrm{mins}$ following flumazenil injection.

Side effects were infrequent and rarely serious. Adverse events probably related to flumazenil included: anxiety and diaphoresis in one patient after 20 $\mu \mathrm{g} / \mathrm{kg}$ flumazenil; headache in one individual; and a brief period $(60 \mathrm{~s})$ of apnea, the latter two after $25 \mu \mathrm{g} / \mathrm{kg}$ flumazenil. The period of apnea occurred in a patient who received $15 \mathrm{mg}$ diazepam.

\section{DISCUSSION}

Flumazenil has been used to antagonize the effects of diazepam and midazolam in a variety of clinical situations. Its effectiveness has been noted in patients undergoing cystoscopy (13), ophthalmological surgery (14), arthroscopy (15) and therapeutic abortion (16). It also shows promise in reversing general anesthesia (22) particularly when a benzodiazepine is given as part of the induction (22). Patients admitted to an intensive care unit with suspected drug overdose who received $1 \mathrm{mg}$ of flumazenil less frequently required gastric lavage, intubation and bladder catheterization than those randomized to placebo (23).

Flumazenil appears to be equally effective in reversing midazolam- as
TABLE 1

Characteristics of treatment groups

\begin{tabular}{lcccccc}
\hline & \multicolumn{7}{c}{ Flumazenil dosage $(\mu \mathrm{g} / \mathrm{kg})$} \\
Parameter & Vehicle & 5 & 10 & 15 & 20 & 25 \\
\hline Male:female & $6: 4$ & $4: 6$ & $5: 5$ & $7: 3$ & $4: 6$ & $5: 5$ \\
ASA class (I/II) & $5 / 5$ & $6 / 4$ & $6 / 4$ & $7 / 3$ & $9 / 1$ & $6 / 4$ \\
Age (years) \pm SD & $36 \pm 12$ & $43 \pm 12$ & $39 \pm 11$ & $42 \pm 13$ & $37 \pm 12$ & $40 \pm 11$ \\
Weight $(\mathrm{kg}) \pm \mathrm{SD}$ & $71 \pm 16$ & $73 \pm 17$ & $68 \pm 13$ & $72 \pm 16$ & $69 \pm 15$ & $71 \pm 8$ \\
Mean flumazenil & 0.00 & 0.37 & 0.68 & 1.07 & 1.39 & 1.78 \\
dose (mg) & & & & & & \\
Diazepam dosage & 0.26 & 0.24 & 0.25 & 0.27 & 0.27 & 0.26 \\
(mg/kg) & \pm 0.04 & \pm 0.04 & \pm 0.06 & \pm 0.02 & \pm 0.04 & \pm 0.04 \\
\hline
\end{tabular}

There were no significant differences between groups. ASA Amercian Society of Anesthesiologists

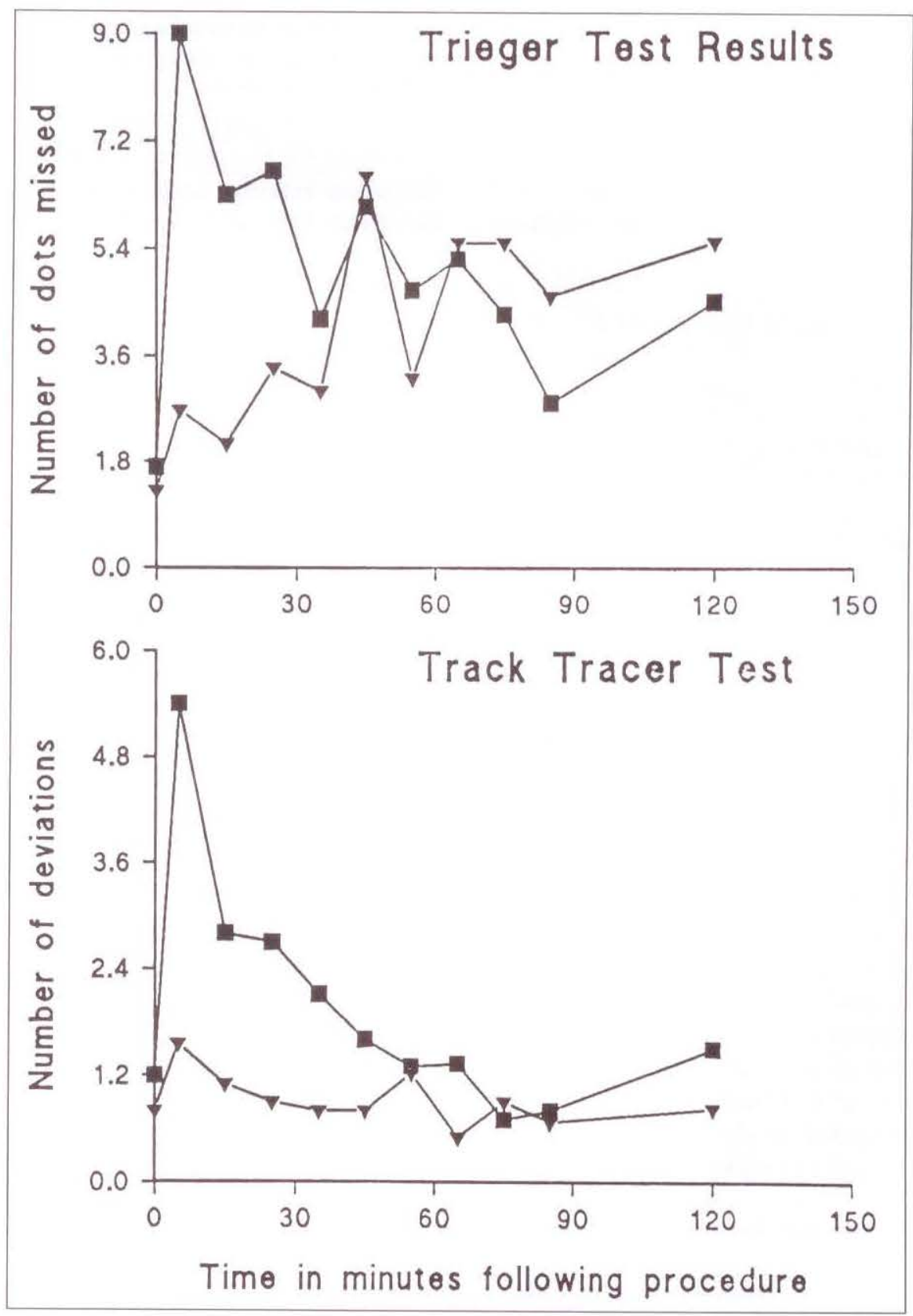

Figure 1) Results of Trieger (top) and Track Tracer (bottom) testing in flumazenil- and placebo-treated patients. Statistically significant differences are noted between both groups until 45 mins after the procedure (ANCOVA, $P<0.01$ ). Vehicle; $\boldsymbol{\Delta}$ Flumazenil $15 \mu \mathrm{g} / \mathrm{kg}$ 
diazepam-induced sedation (24-26). Generally patients are awake and oriented within 5 mins of receiving flumazenil (27).

The present study suggests that flumazenil-treated patients may require a shorter observation period and thus less nursing time following endoscopy. Therefore, patients who receive flumazenil could probably be discharged from the endoscopy suite to a comfortable chair in the recovery area rather than back to their stretcher and cubicle. Potential cost savings in terms of staffing and increased productivity have been suggested (13).

The half-life of flumazenil is relatively short (54 mins) compared with the half-lives of diazepam $(43 \mathrm{~h})$ and midazolam $(2.4 \mathrm{~h})$. In one study $10 \%$ of patients discharged home following flumazenil reversal suddenly fell asleep during the evening (28). The phenomenon has not been reported by other investigators. The present study and others (29) suggest that the effect of flumazenil is most evident in the first hour following induction of sedation. After $1 \mathrm{~h}$ the recovering flumazeniltreated partient does not differ from other benzodiazepine-treated patients.

Anxiety has been reported with rapid administration of high doses of flumazenil (30). In some cases this may be related to the patient's rapid awakening in an unfamiliar environment. None of the patients in the present study was anxious following reversal. A slower rate of administration or limitation of total dose should reduce incidents of anxiety.

The present trial was designed with reference to previously published reports stating the required dosage of flumazenil to be between 20 and $49 \mu \mathrm{g} / \mathrm{kg}$. Surprisingly, the present authors found that all doses of flumazenil were effective up to 45 mins after the procedure compared to placebo. In fact modest amounts $(5 \mu \mathrm{g} / \mathrm{kg})$ were sufficient to rouse the present patients. Even smaller dosages may be effective. The present sample size was inadequate to evaluate all doses - approximately 100 patients are required to exclude any significant difference between any two dosage levels.
Flumazenil was well tolerated and side effects were few and insignificant in the present study. One patient had a brief period of apnea. This may have been related to the dose of diazepam given. The authors are unaware of any study which reported apnea associated with the use of flumazenil. Other investigators have noted that flumazenil reverses the elevation of arterial $\mathrm{PCO}_{2}$, which occurs in diazepam-treated patients (31). Studies of cardiovascular function indicate that there are no significant cardiovascular effects when flumazenil is given to reverse diazepam sedation in patients undergoing cardiac catheterization $(31,32)$.

There is a variety of possible explanations for the lack of significant differences between various dosages of flumazenil. First, although there was a trend towards differences between groups, this sample was not of sufficient size to provide the statistical power required. Second, the amount of diazepam required to induce a relaxed state varied markedly ( 11.5 to $31 \mathrm{mg}$ ). The dose of flumazenil given was based on body weight, not diazepam dose, which might explain why a consistent improvement in recovery as the dose of flumazenil increased could not be demonstrated. However, the average dose of diazepam given did not vary significantly between groups. Third, the patients had not received premedicants such as meperidine. In the authors' experience a premedicant deepens the conscious sedation and allows a lower dose of diazepam to be given; therefore, an opportunity to examine a narrower range of diazepam doses in which to assess the efficacy of the various dosages of flumazenil may have been missed. Finally, it is possible that only a small quantity of flumazenil is required to competitively inhibit the benzodiazepine receptor.

No significant differences between flumazenil-and placebo-treated patients could be demonstrated 45 mins after flumazenil infusion. This could be a problem with the various evaluation methods (Trieger, digit substitution, track tracing and cancellation tests). These tests have been used by other investigators in the assessment of mid- azolam and diazepam; however, their intensive use (every 10 mins) may induce a learning phenomenon which could make differentiation between groups more difficult (21).

The results of this study are in agreement with other reports of the use of flumazenil in the endoscopy suite (26, 28,33). Flumazenil is effective, well tolerated and free from side effects. While there has been variation in the dose of flumazenil used, all studies gave patients between $0.5 \mathrm{mg}$ and $1.0 \mathrm{mg}$.

The present data suggest that all of the flumazenil doses, from $0.37 \mathrm{mg}(5.0$ $\mu \mathrm{g} / \mathrm{kg})$ to $1.78 \mathrm{mg}(25 \mu \mathrm{g} / \mathrm{kg})$, were equally effective in reversing sedation in unpremedicated patients. This is in agreement with previous investigators who have recommended a dose of up to $0.5 \mathrm{mg}$ to reverse diazepam-induced sedation (25). Flumazenil shows promise as a benzodiazepine antagonist. Although adverse effects from medication in the endoscopy unit are rare (34), the addition of flumazenil to the medication cart in the suite is appropriate; however, the routine use of flumazenil to reverse sedation in patients requires further investigation.

ACKNOWLEDGEMENTS: Funding for this project was provided by Hoffmann-La Roche Limited, Canada. The authors acknowledge the efforts of Nancy Racicot, RN, study nurse, as well as Joan Craig, RN and Jessie Darling, RN, endoscopy nurses.

\section{REFERENCES}

1. Hoare AM, Hawkins CF. Upper gastrointestinal endoscopy with or without sedation: Patient's opinions. Br Med J 1976;2:20-3.

2. Thompson DG, Lennard-Jones JE, Evans SJ, Cowan RE, Murray RS, Wright JF. Patients appreciate premedication for endoscopy. Lancet 1980;ii:469-70.

3. Ticktin HE, Trujillo NP. Evaluation of diazepam for pre-endoscopy medication. Am J Dig Dis 1965;10:979-84.

4. Langdon DE, Harlan JR, Bailey RL. Thrombophlebitis with diazepam used intravenously. JAMA 1973;223:184-5.

5. Dundee JW, Halliday NJ, Harper KW, Broaden RN. Midazolam: A review of its pharmacological properties and therapeutic use. Drugs 1984;28:519-43. 
6. Reves JG, Fragen RJ, VinikR, Greenblatt DJ. Midazolam: Pharmacology and uses. Anesthesiology 1985;62:310-24.

7. Sutherland LR, Goldenberg E, Hershfield N, Price L, MacCannell K, Shaffer E. Midazolam in upper gastrointestinal endoscopy: A single-blind dose-finding study. Clin Invest Med 1989;12:99-103.

8. Magni VC, Frost RA, Leung JWC, Cotton PB. A randomized comparison of midazolam and diazepam for sedation in upper gastrointestinal endoscopy. Br ] Anaesth 1983;55:1095-100.

9. Bardham KD, Morris P, Taylor PC, Hinchcliffe RFC. Intravenous sedation for upper gastrointestinal endoscopy; diazepam vs midazolam. Br Med J 1984;288:1046.

10. Mohler B. Benzodiazepine receptors and their ligands. In: Bowery NG, ed. Actions and Interactions of GABA and Benzodiazepines. New York: Raven Press, 1984:155-66.

11. Darragh A, Lambe R, Kenny M, Brick I. Tolerance of healthy volunteers to intravenous administration of the benzodiazepine antagonist Ro 15-1788. Eur J Clin Pharmacol 1983;24:569-70.

12. Brogden RN, Goa KL. Flumazenil - A preliminary review of its benzodiazepine antagonist properties, intrinsic activity and therapeutic use. Drugs 1988;35:448-67.

13. Birch BRP, Anson KM, Clifford E, Miller RA. Day-case surgery: Enhanced recovery with flumazenil. JR Soc Med 1990;83:436-8.

14. Gobeaux D, Sardnal F. Midazolam and flumazenil in ophthalmology. Acta Anaesthesiol Scand 1990;34(Suppl 92):35-8.

15. Zuurmond WWA, van Leeuwen L, Helmers JHJH. Recovery from fixed-dose midazolam-induced anaesthesia and antagonism with flumazenil for outpatient arthroscopy. Acta Anaesthesiol Scand 1989;33:160-3.

16. Hamar O, Garamvolgyi Gy, Kalman A. Fentanyl-midazolam-flumazenil anesthesia for induced abortion. Int J Gynecol Obstet 1989;30:69-72.

17. Amrein R, Leishman B, Bentzinger C, Roncari $\mathrm{G}$. Flumazenil in benzodiazepine antagonism. Med Toxicol 1987;2:411-29.

18. Dripps RD, Lamonte A, Eckenhoff JE. The role of anesthesia in surgical mortality. JAMA 1961;178:261-5.

19. Newman MG, Trieger N, Miller JC. Measuring recovery from anesthesiaA simple test. Anesth Analg 1969;48:136-49.

20. Hart J, Hill HM, Bye CE, Wilkinson RT, Peck AW. The effects of low doses of amylobarbitone sodium and diazepam on human performance. Br J Clin Pharmacol 1976;3:289-98.

21. Dixon RA, Thornton JA. Tests of recovery from anesthesia and sedation: Intravenous diazepam in dentistry. Br J Anaesth 1973;45:207-15.

22. Philip BK, Simpson TH, Hauch MA, Mallampati SR. Flumazenil reverses sedation after midazolam-induced general anesthesia in ambulatory surgery patients. Anesth Analg 1990; 71:371-6

23. Höjer ], Baehrendtz S, Matell G, Gustafsson LL. Diagnostic utility of flumazenil in coma with suspected poisoning: A double blind, randomised controlled study. Br Med J 1990;301:1308-11.

24. Jensen S, Knudsen L, Kirkegaard L, Kruse A, Knudsen EB. Flumazenil used for antagonizing the central effects of midazolam and diazepam in outpatients. Acta Anaesthesiol Scand 1989;33:26-8.

25. Andrews PJD, Wright DJ, Lamont
MC. Flumazenil in the outpatient. A study following midazolam as sedation for upper gastrointestinal endoscopy. Anaesthesia 1990;45:445.58.

26. Bartelsman JFWM, Sars PRA, Tytgat GNJ. Flumazenil used for reversal of midazolam-induced sedation in endoscopy outpatients. Gastrointest Endosc 1990;36:S9-12.

27. Kirkegaard L, Knudsen L, Jensen S, Kruse A. Benzodiazepine antagonist Ro 15-1788. Anesthesia 1986;41:1184-8.

28. Holloway AM, Logan DA.The use of flumazenil to reverse diazepam sedation after endoscopy. Eur ] Anesthesiol 1988;(Suppl 2):191-8.

29. Whithan JG. The use of midazolam and flumazenil in diagnostic and short surgical procedures. Acta Anaesthesiol Scand 1990;34(Suppl 92): 16-20.

30. Klotz U, Kanto J. Pharmacokinetics and clinical use of flumazenil (Ro 15-1788). Clin Pharmacokinet 1988;14:1-12.

31. Geller E, Halpern P, Chernilas J, Niv D, Miller HB. Cardiorespiratory effects of antagonism of diazepam sedation with flumazenil in patients with cardiac disease. Anesth Analg 1991;72:207-11.

32. Croughwell ND, Reves JG, Will CJ, Kasson BJ, Goodman DK. Safety of rapid administration of flumazenil in patients with ischaemic heart disease. Acta Anaesthesiol Scand 1990;34(Suppl 92):55-8.

33. Birkenfeld S, Ferderico C, DermanskyAvni Y, Bruck R, Melzer E, Bar-Meir S. Double blind controlled trial of flumazenil in patients who underwent upper gastrointestinal endoscopy. Gastrointest Endosc 1989;35:519-22.

34. Shahmir M, Schuman BM. Complications of fiberoptic endoscopy. Gastrointest Endosc $1980 ; 26: 86-91$. 


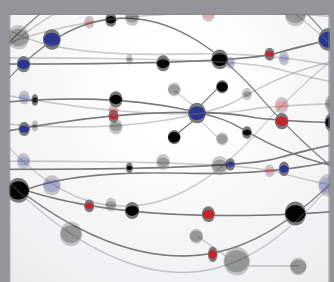

The Scientific World Journal
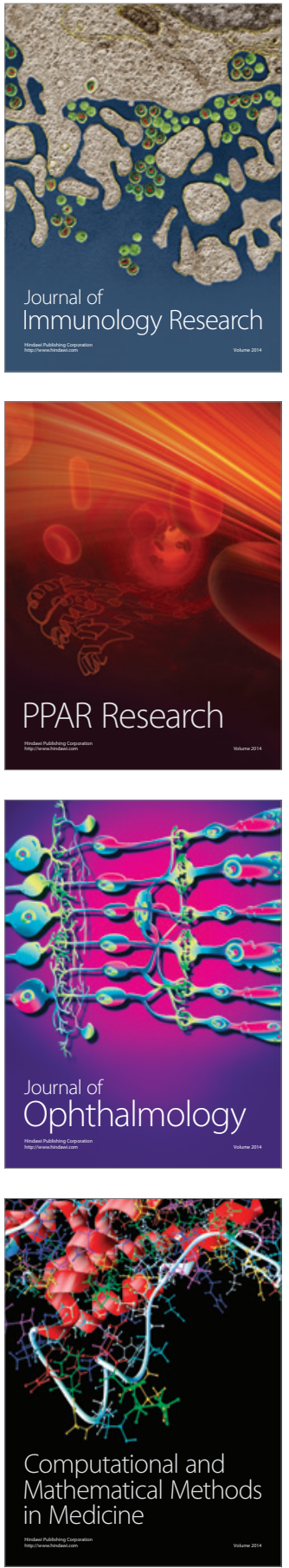

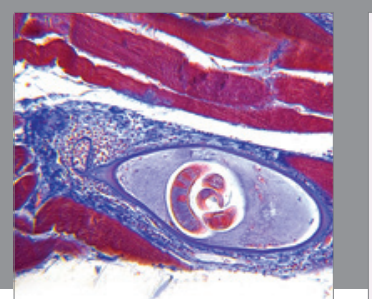

Gastroenterology Research and Practice

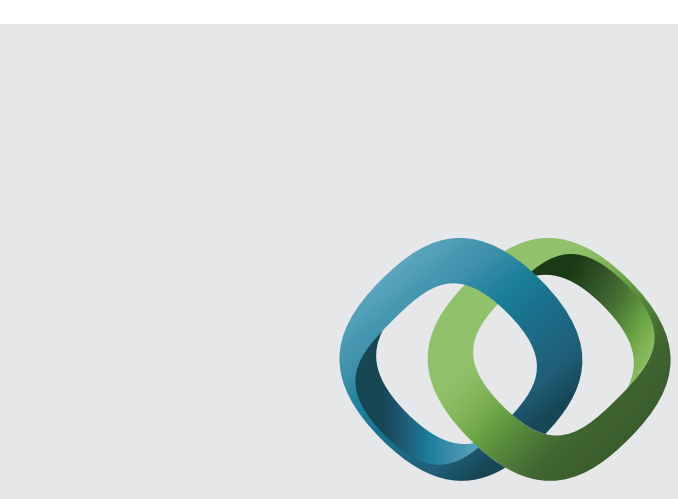

\section{Hindawi}

Submit your manuscripts at

http://www.hindawi.com
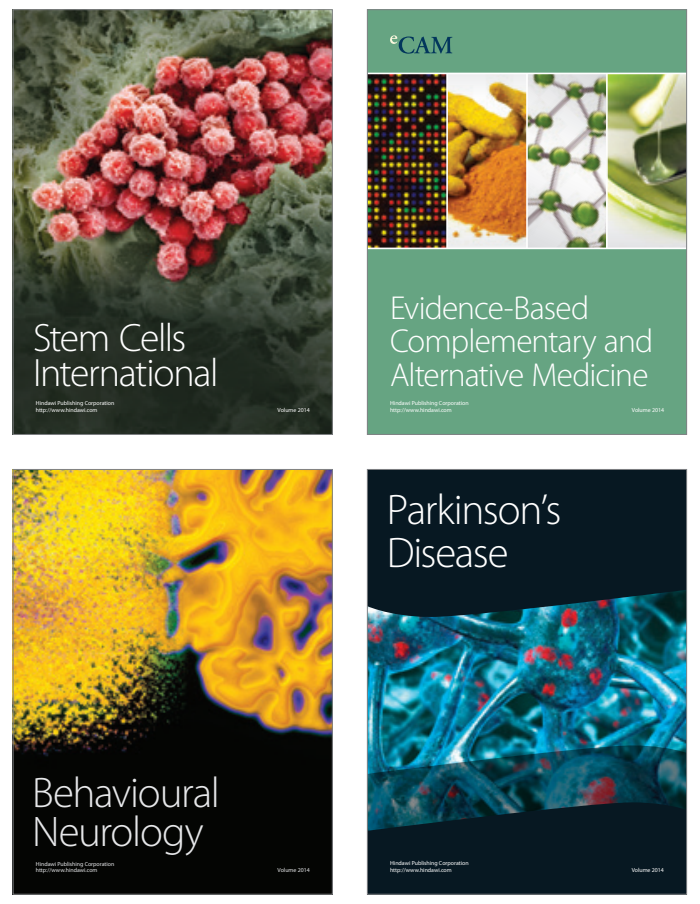
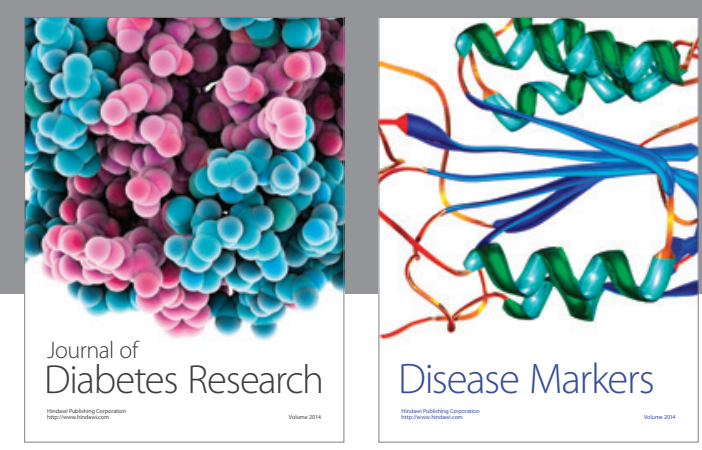

Disease Markers
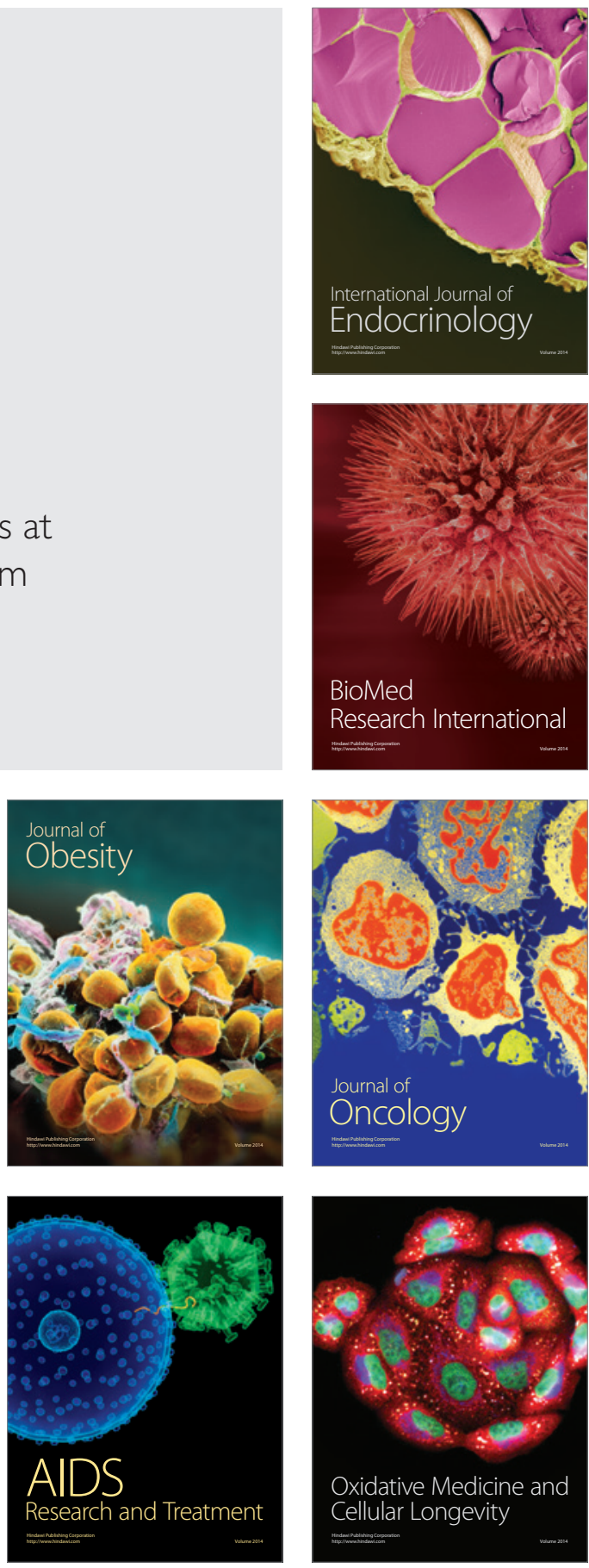